\title{
Comparison of Cisatracurium Versus Atracurium in Early ARDS
}

\author{
Leanne Moore PharmD, Charles Joseph Kramer PharmD, Sophie Delcoix-Lopes MSc, and \\ Ariel M Modrykamien MD
}

\begin{abstract}
BACKGROUND: Administration of cisatracurium in severe ARDS decreases in-hospital mortality. Whether clinical outcomes are cisatracurium-specific or related with all neuromuscular blockers is unknown. This study aimed to compare outcomes in severe ARDS patients treated with cisatracurium versus atracurium. METHODS: Patients admitted in ICUs with a diagnosis of severe ARDS and treated with neuromuscular blocking agents within $72 \mathrm{~h}$ of diagnosis were included. Subjects treated with cisatracurium versus atracurium were compared. The primary outcome was improvement in oxygenation, defined as the difference of $\mathrm{P}_{\mathrm{aO}_{2}} / \mathrm{F}_{\mathrm{IO}_{2}}$ at $72 \mathrm{~h}$ post-initiation of neuromuscular blocking agents. Secondary outcomes were ventilator-free days at day 28 , ICU and hospital lengths of stay, and hospital mortality. RESULTS: Seventy-six subjects with ARDS were included in the study. Eighteen subjects $(24 \%)$ were treated with atracurium, whereas $58(76 \%)$ were treated with cisatracurium. Equivalent dosages of sedation and analgesia as well as use of brain function monitoring technology were similar between both groups. There were no differences in clinical outcomes. Specifically, improvement of $\mathrm{P}_{\mathrm{aO}} / \mathrm{F}_{\mathrm{IO}_{2}}$ was a median (interquartile range [IQR]) of 65 $(25-162)$ in the atracurium group and 66 (IQR 16-147) in the cisatracurium group $(P=.65)$. Ventilator-free days at day 28 were $13 \mathrm{~d}$ (IQR 0-22 d) and $15 \mathrm{~d}$ (IQR 8-21 d) in the atracurium and cisatracurium groups, respectively $(P=.72)$. ICU length or stay was $18 \mathrm{~d}$ (IQR 8-34 d) in the atracurium group and $15 \mathrm{~d}$ (IQR 9-22 d) in the cisatracurium group $(P=.34)$. In-hospital mortality was $50 \%$ for the atracurium population and $62 \%$ for the cisatracurium group $(P=.42)$ CONCLUSIONS: Among subjects with early severe ARDS, the utilization of atracurium versus cisatracurium within $\mathbf{7 2} \mathrm{h}$ of admission was not associated with significant differences in clinical outcomes. Key words: ARDS; neuromuscular blockers; mechanical ventilation; oxygenation. [Respir Care 2017;62(7):947-952. (C) 2017 Daedalus Enterprises]
\end{abstract}

\section{Introduction}

ARDS and the condition previously called acute lung injury (ALI) are both characterized by rapid onset of re-

\footnotetext{
Drs Moore and Kramer are affiliated with the Department of Pharmacy, Ms Delcoix-Lopes is affiliated with the Department of Clinical Effectiveness, and Dr Modrykamien is affiliated with the Department of Medicine, Division of Pulmonary and Critical Care Medicine, Baylor University Medical Center, Dallas, Texas.

The authors have disclosed no conflicts of interest.

Correspondence: Ariel M Modrykamien MD, Baylor University Medical Center, 3600 Gaston Avenue, Wadley Tower 960, Dallas, TX 75246. E-mail: ariel.modrykamien@baylorhealth.edu.
}

DOI: $10.4187 /$ respcare. 05102 spiratory failure following a variety of direct and indirect lung insults. Since its description, many definitions have been widely used for enrollment of ARDS patients in therapeutic clinical trials. ${ }^{1}$ Nevertheless, in 2011, the European Society of Intensive Care Medicine proposed the most recent Berlin definition. ${ }^{2}$ In brief, the term acute lung injury was eliminated, and ARDS has been categorized as mild, moderate, and severe based on $\mathrm{P}_{\mathrm{aO}} / \mathrm{F}_{\mathrm{IO}_{2}}$ and levels of PEEP. Since the publication of the ARMA trial, ${ }^{3}$ lungprotective mechanical ventilation has become the cornerstone management strategy for ARDS. Nevertheless, in cases of hypoxemia refractory to conventional therapy, other strategies have been utilized, such as prone positioning, ${ }^{4}$ high levels of PEEP, ${ }^{5}$ airway pressure release ventilation $^{6}$, extracorporeal membrane oxygenation, ${ }^{7}$ inhaled nitric oxide, ${ }^{8}$ and corticosteroids. ${ }^{9}$ Despite the aforementioned strategies, patients with ARDS may still be exposed 


\section{Cisatracurium vs Atracurium IN EARly ARDS}

to atelectrauma and barotrauma due to suboptimal ventilator strategies. Hence, the use of neuromuscular blocking agents (NMBAs) has been proposed as adjuvant therapy with successful results. Among these agents, those categorized as non-depolarizing have been extensively studied. Particularly, atracurium and one of its 10 isomers, cisatracurium, have been used in clinical practice. ${ }^{10}$ Both agents spontaneously degrade at physiological $\mathrm{pH}$ via Hofmann elimination to yield laudanosine. ${ }^{11}$ Because Hofmann elimination is an organ-independent degradative mechanism, there is little or no risk when using these medications in patients with liver or renal disease. However, the metabolite laudanosine is cleared primarily via renal excretion, and its accumulation in patients with renal failure may lead to epileptogenic activity and cardiovascular effects, such as hypotension and bradycardia. Prior studies showed that plasma concentrations of laudanosine are lower with cisatracurium than those seen with atracurium. ${ }^{12}$ Furthermore, histamine release upon administration of atracurium, with its consequent cutaneous flushing, hypotension, and tachycardia, were not described with the use of cisatracurium. ${ }^{13}$ Based on its safety profile, cisatracurium became the preferred choice for the treatment of patients with ARDS. Particularly, a multi-center, doubleblinded, randomized control trial, which included subjects with severe ARDS and compared the use of cisatracurium versus placebo, showed a decrease in mortality with the study drug. ${ }^{14}$ Despite these encouraging results, further questions still remained unanswered. First, were these positive outcomes cisatracurium-specific or associated with the use of any neuromuscular blocking agent? Second, are other clinical outcomes (ie, improvement of oxygenation) different with the use of cisatracurium compared with other agents? To address the aforementioned questions, we retrospectively studied a group of subjects admitted with a diagnosis of ARDS and treated with 2 neuromuscular blocking agents as adjuvant therapy, atracurium and cisatracurium.

\section{Methods}

The study was approved by the institutional review board of Baylor University Medical Center (Study 015-115). A retrospective evaluation of a consecutive series of patients admitted from July 2012 to July 2015 to all ICUs at Baylor University Medical Center with a diagnosis of ALI/ARDS and treated with neuromuscular blocking agents was performed from an administrative database. Once the list of patients was obtained, diagnoses of ALI and ARDS were confirmed by reviewing patients' medical records and $\mathrm{P}_{\mathrm{aO}_{2}} / \mathrm{F}_{\mathrm{IO}_{2}}$ values at the time of diagnosis. The patients were then reclassified as having mild, moderate, or severe ARDS according to the Berlin criteria. Of note, because the study aimed at evaluating the effect of neuromuscular blockers

\section{QUICK LOOK}

\section{Current knowledge}

In patients with severe ARDS, early administration of neuromuscular blocking agents (NMBAs) has been associated with positive clinical outcomes. Specifically, the use of cisatracurium showed improvement in 90-d survival and ventilator-free days, without increasing muscle weakness. Cisatracurium presents a safe pharmacological profile, because accumulation of metabolites is minimal, and it is not associated with histamine release. However, its cost is high compared with other non-depolarizing NMBAs, precluding its broader use.

\section{What this paper contributes to our knowledge}

We compared outcomes in subjects with ARDS treated with cisatracurium versus atracurium. Clinical outcomes in subjects with severe ARDS, such as improvement in oxygenation, ventilator-free days, hospital and ICU lengths of stay, and hospital mortality, were not significantly different between subjects treated with these agents. However, important differences in costs were found. Therefore, atracurium may be an acceptable substitute in institutions where cisatracurium is not available.

in early ARDS, we included only subjects in whom neuromuscular blocker agents were used within $72 \mathrm{~h}$ postARDS presentation. Also, to study subjects with severe ARDS, only those with $\mathrm{P}_{\mathrm{aO}_{2}} / \mathrm{F}_{\mathrm{IO}_{2}}$ of $<150$ on admission were included. Patients younger than 18 y old, pregnant women, patients already treated with mechanical ventilation for other reasons before the ARDS diagnosis, patients started on NMBAs later than $72 \mathrm{~h}$ after ARDS diagnosis, patients receiving extracorporeal membrane oxygenation treatment, and patients with chronic liver disease and/or severe systolic heart failure were excluded from the study. Patients treated with inhaled vasodilators (ie, inhaled nitric oxide) were excluded as well. Demographic data, such as age, sex, body mass index, Acute Physiology and Chronic Health Evaluation II (APACHE II), type of ICU admission (medical, surgical, or neurological), and cause for ARDS were collected. Also, clinical data involving $\mathrm{P}_{\mathrm{aO}_{2}} / \mathrm{F}_{\mathrm{IO}_{2}}$ at initiation of NMBAs and $72 \mathrm{~h}$ later; drugs and dosage used for sedation, analgesia, and neuromuscular blockage; the need for prone positioning; high-frequency oscillatory ventilation; vasopressor requirements (defined as $\geq 60 \mathrm{~min}$ receiving vasopressors); and high-dose corticosteroids (defined as $0.5 \mathrm{mg} / \mathrm{kg}$ every $6 \mathrm{~h}$ ) for ARDS were collected as well. Mechanical ventilation information, such as mode of ventilation, tidal volumes (expressed as $\mathrm{mL} / \mathrm{kg}$ of ideal body weight), and plateau pressures, were included. To 
collect these data, documentation from ventilator checks routinely performed by respiratory therapists was examined. Average daily values of tidal volumes and plateau pressures were obtained throughout the entire time receiving mechanical ventilation. Furthermore, modes of mechanical ventilation were collected.

To report dosage of sedation therapy, all sedatives were calculated as midazolam dose equivalents based on previously described formulas. Specifically, for propofol, total dose divided by 43 represented the equivalent total midazolam dose. ${ }^{15}$ The aforementioned dose, divided by number of days receiving NMBAs represented the daily dose. Furthermore, daily dose was normalized based on dosing weight (actual body weight). The same process was followed to calculate midazolam equivalents from lorazepam. In this case, total lorazepam equivalents multiplied by 2 represented the total midazolam equivalent dose. ${ }^{16}$ All patients used fentanyl as preferred analgesia, so no conversion was needed. Subjects were divided into 2 groups based on the drug utilized for neuromuscular blockage: one group composed of ARDS subjects paralyzed with a continuous dose of cisatracurium; another group composed of subjects paralyzed with a continuous dose of atracurium. The allocation to one group or the other was based on availability of medication. Subjects were treated with cisatracurium as the first choice. In situations in which there was a shortage of cisatracurium, subjects were treated with atracurium. Train-of-four monitoring of ulnar or facial nerves was used for NMBA titration. Train-of-four of 2 of 4 initial twitches was considered appropriate paralysis. Clinical outcomes were compared between both groups. The primary outcome of the study was improvement in oxygenation, defined as the difference of $\mathrm{P}_{\mathrm{aO}_{2}}$ / $\mathrm{F}_{\mathrm{IO}_{2}}$ at $72 \mathrm{~h}$ post-initiation of NMBAs and its baseline (at initiation). Secondary outcomes were ventilator-free days at day 28, ICU and hospital lengths of stay, and hospital mortality. Furthermore, costs of NMBA therapy per subject were calculated. To assess costs, the average wholesale price of cisatracurium (vial $200 \mathrm{mg}$ / $20 \mathrm{~mL}$ ) and atracurium (vial $100 \mathrm{mg} / 10 \mathrm{~mL}$ ) were utilized. Total amounts of NMBAs per subject (in $\mathrm{mg}$ ) were calculated and multiplied by average wholesale prices.

\section{Statistics}

Categorical variables were compared between groups using the Fisher exact test. Student's $t$ test was used to compare normally distributed continuous variables, such as age, body mass index, and APACHE II scores. A non-parametric test, the Wilcoxon rank-sum test, was used for hospital length of stay, ICU length of stay, ventilator-free days, paralytic length of treatment, average fentanyl dose $/ 24 \mathrm{~h}$, average midazolam and propo-
Table 1. Cause of ARDS Among Included Subjects

\begin{tabular}{lccr}
\hline \hline \multicolumn{1}{c}{ Etiology } & Cisatracurium & Atracurium & $P$ \\
\hline Bacterial pneumonia & $34(58)$ & $8(44)$ & .41 \\
Non-pulmonary sepsis & $4(7)$ & $3(17)$ & .34 \\
Viral pneumonia & $4(7)$ & $0(0)$ & .56 \\
Fungal pneumonia & $4(7)$ & $1(6)$ & $>.99$ \\
Drug-induced ARDS & $1(2)$ & $2(11)$ & .14 \\
Pancreatitis & $1(2)$ & $0(0)$ & $>.99$ \\
Interstitial lung disease & $2(3)$ & $0(0)$ & $>.99$ \\
Diffuse alveolar hemorrhage & $1(2)$ & $0(0)$ & $>.99$ \\
Radiation therapy & $1(2)$ & $0(0)$ & $>.99$ \\
Not identified & $6(10)$ & $4(22)$ & .23 \\
Total & $58(100)$ & $18(100)$ & \\
& & & \\
Results are $n$ (\%). & & & \\
\hline
\end{tabular}

fol dose $/ 24 \mathrm{~h}$, weight-adjusted midazolam equivalents, weight-adjusted total daily dose of fentanyl and NMBAs, stay receiving NMBAs, and time (minutes) elapsed from ARDS diagnosis to initiation of neuromuscular paralysis. Those variables do not satisfy the normality assumptions, which is required for the parametric test. Statistical analysis was performed with the SAS Enterprise Guide statistical package 6.1 (SAS Institute, Cary, North Carolina).

\section{Results}

Over the study period, 510 patients were diagnosed with ARDS and treated with NMBAs based on the administrative database. Of these patients, 434 (85\%) were excluded. Within the excluded patients, 213 (49\%) did not fulfill the diagnosis of ARDS after further assessment. Seventy-eight of the patients (18\%) changed advance directives toward comfort measures. Sixty-one patients $(14 \%)$ were treated with extracorporeal membrane oxygenation therapy, and $56(13 \%)$ lacked information to pursue further analysis. Twenty-two patients (5\%) had chronic liver disease, and $4(1 \%)$ had severe systolic heart failure. Consequently, only 76 ARDS patients treated with NMBAs fulfilled the inclusion criteria. Eighteen and 58 subjects were included in the atracurium and cisatracurium groups, respectively. Table 1 shows causes of ARDS among all subjects included in the study. Table 2 reveals a comparison of demographic and clinical information between the atracurium and cisatracurium groups. Of note, of 76 subjects included in the study, only $45(59 \%)$ had brain function monitoring during neuromuscular blockage. Specifically, these subjects were monitored with SedLine brain function monitoring (Masimo, Irvine, California), which provides 4 simultaneous electroencephalography channels to enable continuous assess- 
Table 2. Demographic and Clinical Information

\begin{tabular}{|c|c|c|c|}
\hline Variable & Atracurium $(n=18)$ & Cisatracurium $(n=58)$ & $P$ \\
\hline Age, mean $\pm \mathrm{SD}, \mathrm{y}$ & $49 \pm 17$ & $53 \pm 12$ & .24 \\
\hline Male, $n(\%)$ & $5(28)$ & $34(59)$ & .03 \\
\hline $\mathrm{BMI}$, mean $\pm \mathrm{SD} \mathrm{kg} / \mathrm{m}^{2}$ & $29 \pm 7$ & $28 \pm 6$ & .56 \\
\hline APACHE II, mean \pm SD & $25 \pm 8$ & $24 \pm 7$ & .63 \\
\hline High-dose steroid use, $n(\%)$ & $8(44)$ & $26(45)$ & $>.99$ \\
\hline Vasopressor use, $n(\%)$ & $13(72)$ & $45(78)$ & .75 \\
\hline Fentanyl weight adjusted, median (IQR) $\mu \mathrm{g} / \mathrm{kg} / \mathrm{d}$ & $7.5(6-11)$ & $8(5-11)$ & .97 \\
\hline Weight-adjusted midazolam equivalents, median (IQR) $\mathrm{mg} / \mathrm{kg} / \mathrm{d}$ & $2(1-4)$ & $2(2-3)$ & .42 \\
\hline Neuromuscular blocker dose, median (IQR) $\mu \mathrm{g} / \mathrm{kg} / \mathrm{min}$ & $1.9(0.5-3.0)$ & $2.5(1.5-4.0)$ & 051 \\
\hline Duration of neuromuscular blocker, median (IQR) d & $2.5(1.8-3.6)$ & $2.6(1.7-4.7)$ & .86 \\
\hline $\begin{array}{l}\text { Time from ARDS diagnosis to initiation of neuromuscular } \\
\text { blocker, median (IQR) min }\end{array}$ & $212(86-464)$ & $158(65-379)$ & .38 \\
\hline $\begin{array}{l}\text { BMI = body mass index } \\
\text { APACHE = Acute Physiology and Chronic Health Evaluation } \\
\text { IQR = interquartile range }\end{array}$ & & & \\
\hline
\end{tabular}

Table 3. Mechanical Ventilation Strategies

\begin{tabular}{lccr}
\hline \hline \multicolumn{1}{c}{ Variable } & $\begin{array}{c}\text { Atracurium } \\
(n=18)\end{array}$ & $\begin{array}{c}\text { Cisatracurium } \\
(n=58)\end{array}$ & \multicolumn{1}{c}{$P$} \\
\hline Volume control mode, $n(\%)$ & $9(50)$ & $30(52)$ & $>.99$ \\
Pressure control mode, $n(\%)$ & $7(39)$ & $17(29)$ & .56 \\
APRV, $n(\%)$ & $1(5)$ & $7(12)$ & .67 \\
$\mathrm{HFOV}, n(\%)$ & $1(5)$ & $4(7)$ & $>.99$ \\
Prone positioning, $n(\%)$ & $4(22)$ & $14(24)$ & $>.99$ \\
Tidal volume, mean $\pm \mathrm{SD}$ & $8.2 \pm 2.4$ & $7.5 \pm 2.5$ & .29 \\
$\quad \mathrm{~mL} / \mathrm{kg}$ ideal body weight & & & \\
Plateau pressure, mean $\pm \mathrm{SD}$ & $30.4 \pm 5.2$ & $30.7 \pm 5.5$ & .83 \\
$\quad \mathrm{~cm} \mathrm{H}_{2} \mathrm{O}$ & & & \\
& & & \\
\hline APRV $=$ airway pressure release ventilation & & & \\
HFOV $=$ high-frequency oscillatory ventilation & & & \\
\hline
\end{tabular}

ment of both sides of the brain. When we assessed utilization of brain function monitoring between both groups, there was no statistically significant difference in the utilization of this technology between the atracurium and cisatracurium groups (44\% vs $64 \%$, respectively, $P=.17$ ). Table 3 shows mechanical ventilation strategies, such as mode of mechanical ventilation, tidal volumes, and plateau pressures. Table 4 shows results of primary and secondary outcomes. Costs of NMBAs per subject were significantly different. Based on an average wholesale price of cisatracurium $(200 \mathrm{mg} / 20 \mathrm{~mL})$ and atracurium $(100 \mathrm{mg} / 10 \mathrm{~mL})$ of United States $\$ 324.60$ and $\$ 15.60$, respectively, the total cost/subject of cisatracurium was $\$ 2,256$, compared with $\$ 166$ for atracurium (data for atracurium and cisatracurium from Lexicomp Online, Lexi-Drugs, www.lexi.com, Accessed December 2, 2016). Importantly, as shown in Table 2, lengths of stay receiving NMBAs and the dose/subject were not significantly different between both groups.

\section{Discussion}

The present study shows no difference between the use of atracurium and cisatracurium among subjects diagnosed with early ARDS and treated with NMBAs. Specifically, there were no significant differences in terms of improvement of oxygenation, ventilator-free days, ICU and hospital lengths of stay, and hospital mortality.

This is the first study published in the English literature that has compared the effect of 2 different NMBAs on clinical outcomes in subjects with ARDS. The utilization of these types of drugs in patients with respiratory failure has been attempted for $>30$ years. Particularly, in 1984, Bishop ${ }^{17}$ reported the use of a single bolus of pancuronium in 9 subjects with ALI/ARDS. No effects were seen in hemodynamic variables or oxygenation. Since that report, other authors attempted similar experiences, obtaining negative results or a lack of results. ${ }^{18,19}$ Of note, it is worth mentioning that, in addition to the observational nature of these reports, the number of subjects included in each of these experiences was very small (1-13 subjects), which could have precluded any evident effect of the study drug. In 2002, the first prospective randomized control trial, which included the use of continuous infusion of cisatracurim for $2 \mathrm{~h}$, was published. ${ }^{14}$ In this study, 102 subjects with ARDS and a $\mathrm{P}_{\mathrm{aO}_{2}} / \mathrm{F}_{\mathrm{IO}_{2}}$ of $<200$ were randomized to receive cisatracurium drips aiming at 2 different levels of paralysis monitored by train-of-four assessments. No placebo group was included in this trial. The study revealed an improvement in $\mathrm{P}_{\mathrm{aO}_{2}} / \mathrm{F}_{\mathrm{IO}_{2}}$ and plateau pressures in both groups, showing no differences paralyzing to train-of-four of 0 of 4 or 2 of 4 , respectively. Two years after this publication, Gainnier et al ${ }^{20}$ published a multi-center prospective randomized control trial, which included 56 ARDS subjects with $\mathrm{P}_{\mathrm{aO}_{2}} / \mathrm{F}_{\mathrm{IO}_{2}}<150$ and PEEP $>5 \mathrm{~cm} \mathrm{H} \mathrm{H}_{2} \mathrm{O}$. Sub- 
Table 4. Outcome Data: Comparison Between Atracurium and Cisatracurium Groups

\begin{tabular}{|c|c|c|c|}
\hline Outcome & Atracurium $(n=18)$ & Cisatracurium $(n=58)$ & $P$ \\
\hline $\mathrm{P}_{\mathrm{aO}_{2}} / \mathrm{F}_{\mathrm{IO}_{2}}$ before NMBA, median (IQR) & $97(68-140)$ & $100(75-140)$ & .67 \\
\hline $\mathrm{P}_{\mathrm{aO}_{2}} / \mathrm{F}_{\mathrm{IO}_{2}} 72 \mathrm{~h}$ after NMBA, median (IQR) & $165(77-262)$ & $178(121-255)$ & .65 \\
\hline $\mathrm{P}_{\mathrm{aO}_{2}} / \mathrm{F}_{\mathrm{IO}_{2}}$ improvement at $72 \mathrm{~h}$, median (IQR) & $65(25-162)$ & $66(16-147)$ & .65 \\
\hline Ventilator-free days at day 28 , median (IQR) d & $13(0-22)$ & $15(8-21)$ & .72 \\
\hline ICU length of stay, median (IQR) d & $18(8-34)$ & $15(9-22)$ & .34 \\
\hline Hospital length of stay, median (IQR) d & $28(16-39)$ & $18(10-28)$ & .09 \\
\hline Hospital mortality, $n(\%)$ & $9(50)$ & $36(62)$ & .42 \\
\hline $\begin{array}{l}\text { NMBA = neuromuscular blocking agent } \\
\mathrm{IQR}=\text { interquartile range }\end{array}$ & & & \\
\hline
\end{tabular}

jects were randomized to a 48-h infusion of cisatracurium versus placebo, and the primary outcome was oxygenation over a 120 -h time period. Interestingly, the study drug revealed an improvement in oxygenation at 48, 96, and $120 \mathrm{~h}$ post-randomization as well as a reduction of levels of PEEP required to achieve oxygenation. This study presented the first evidence of beneficial effects of NMBAs on physiologic outcomes. In 2006, Forel et al ${ }^{21}$ published a multi-center randomized control study, which compared the infusion of NMBAs versus placebo in relation to the inflammatory response in subjects with ARDS. Briefly, as in the previously described trial, subjects were randomized to a 48-h infusion of cisatracurium versus placebo. Proinflammatory markers, such as tumor necrosis factor- $\alpha$, interleukin- $1 \beta$, interleukin- 6 , and interleukin- 8 were measured at baseline and $48 \mathrm{~h}$ later. Notably, there was a significant reduction of pro-inflammatory markers in the group treated with cisatracurium. Consequently, based on prior experiences that demonstrated physiologic and biologic benefits, Papazian et al ${ }^{14}$ published a multi-center, double-blinded, and randomized control trial, which included 340 subjects with severe ARDS. The study compared the use of cisatracurium versus placebo. All subjects were sedated, titrating the Ramsay sedation score to 6 (no response on glabelar tap). Muscle paralysis monitoring was not allowed in order to maintain study blinding. As a result, cisatracurium was associated with decreased adjusted 90 -d mortality ( $31.6 \%$ vs $40.7 \%, P=.08)$. Furthermore, mortality at $28 \mathrm{~d}$ was $23.7 \%$ in the cisatracurium group and $33.3 \%$ in the placebo group $(P=.050)$.

The aforementioned studies showed a clear benefit of cisatracurium in a variety of outcomes in subjects with severe ARDS. Nevertheless, these studies only used cisatracurium as the study drug. Therefore, it is unknown whether the effectiveness is cisatracurium-specific or could be extrapolated to other NMBAs.

This question becomes particularly relevant because some health-care facilities may not include cisatracurium in their formulary or may undergo a cisatracurium shortage at times. Additionally, the selection of NMBAs pres- ents important financial implications for health-care organizations, as reported previously ${ }^{16}$ and confirmed in the present study. Consequently, our study presents many strengths. First, it addresses whether the effects of NMBAs in subjects with ARDS are associated with a particular medication or could be extrapolated to other ones. Second, it includes subjects with severe ARDS, whose diagnoses were confirmed after reviewing case by case from an initial administrative database. Third, to assess clinical outcomes accurately, many other important variables were included, such as mode of mechanical ventilation, tidal volumes, plateau pressures, use of rescue therapies for ARDS (ie, high-frequency oscillatory ventilation, prone positioning, corticosteroids), equivalent doses of sedation and analgesia, and presence of shock. Total dose of NMBAs, time from diagnosis to initiation of paralysis, and duration of NMBAs were accounted for as well. Despite the aforementioned strengths, many limitations were present, as well. First, the retrospective nature of the study exposes it to information and recall bias. By carefully reviewing every medical record to confirm the diagnosis of ARDS, we attempted to minimize this bias. Nevertheless, possible missing or erroneous information may be unavoidable in this type of study. Second, despite the fact that $40-60 \%$ of the subjects were managed with brain function monitoring, and both groups received similar equivalent dosages of sedation agents, it is unknown whether both groups were balanced in terms of depth of sedation. It is possible that despite receiving similar doses of sedatives, the effect on sedation may have been different between groups, directly affecting some clinical outcomes, such as ventilator-free days or length of stay in the ICU. Third, it is possible that the small number of subjects included in the study precludes the detection of statistically significant differences due to lack of power. Last, possible adverse effects associated with laudanosine accumulation or histamine release in the atracurium group, such as seizures, hypotension, or tachycardia, were not collected.

In summary, our study is the first one to compare effects on clinical outcomes between 2 NMBAs in subjects diag- 


\section{Cisatracurium vs Atracurium in EARLy ARDS}

nosed with early ARDS. No differences in terms of improvement of oxygenation, ventilator-free days, ICU or hospital lengths of stay, or hospital mortality were found. Nevertheless, significant differences in costs were found. Further prospective studies analyzing impact on clinical outcomes and cost-effectiveness/cost-utilization will be needed to assess whether the proven effect of cisatracurium can be extrapolated to other NMBAs.

\section{REFERENCES}

1. Bernard GR, Artigas A, Brigham KL, Carlet J, Falke K, Hudson L, et al. The American-European Consensus Conference on ARDS. Definitions, mechanisms, relevant outcomes, and clinical trial coordination. Am J Respir Crit Care Med 1994;149(3 Pt 1):818-824.

2. Ferguson ND, Fan E, Camporota L, Antonelli M, Anzueto A, Beale $\mathrm{R}$, et al. The Berlin definition of ARDS: an expanded rationale, justification, and supplementary material. Intensive Care Med 2012; 38(10):1573-1582.

3. The Acute Respiratory Distress Syndrome Network. Ventilation with lower tidal volumes as compared with traditional tidal volumes for acute lung injury and the acute respiratory distress syndrome. N Engl J Med 2000;342(18):1301-1308.

4. Guerin C, Reignier J, Richard JC. Prone positioning in the acute respiratory distress syndrome. N Engl J Med 2013;369(10):980-981.

5. Briel M, Meade M, Mercat A, Brower RG, Talmor D, Walter SD, et al. Higher vs lower positive end-expiratory pressure in patients with acute lung injury and acute respiratory distress syndrome: systematic review and meta-analysis. JAMA 2010;303(9):865-873.

6. Putensen C, Zech S, Wrigge H, Zinserling J, Stüber F, Von Spiegel T, Mutz, N. Long-term effects of spontaneous breathing during ventilatory support in patients with acute lung injury. Am J Respir Crit Care Med 2001;164(1):43-9.

7. Peek GJ, Clemens F, Elbourne D, Firmin R, Hardy P, Hibbert C, et al. CESAR: conventional ventilatory support vs extracorporeal membrane oxygenation for severe adult respiratory failure. BMC Health Serv Res 2006;6:163.

8. Adhikari NK, Burns KE, Friedrich JO, Granton JT, Cook DJ, Meade MO. Effect of nitric oxide on oxygenation and mortality in acute lung injury: systematic review and meta-analysis. BMJ 2007; 334(7597):779.
9. Meduri GU, Marik PE, Chrousos GP, Pastores SM, Arlt W, Beishuizen A, et al. Steroid treatment in ARDS: a critical appraisal of the ARDS network trial and the recent literature. Intensive Care Med 2008;34(1):61-69.

10. Stenlake JB, Waigh RD, Urwin J, Dewar GH, Coker GG. Atracurium: conception and inception. Br J Anaesth. 1983;55(Suppl 1):3S$10 \mathrm{~S}$.

11. Dear GJ, Harrelson JC, Jones AE, Johnson TE, Pleasance S. Identification of urinary and biliary conjugated metabolites of the neuromuscular blocker $51 \mathrm{~W} 89$ by liquid chromatography/mass spectrometry. Rapid Commun Mass Spectrom 1995;9(14):1457-1464.

12. Fodale V, Santamaria LB. Laudanosine, an atracurium and cisatracurium metabolite. Eur J Anaesthesiol 2002;19(7):466-473.

13. Savarese JJ, Wastila WB. The future of the benzylisoquinolinium relaxants. Acta Anaesthesiol Scand Suppl 1995;106:91-93.

14. Papazian L, Forel JM, Gacouin A, Penot-Ragon C, Perrin G, Loundou A, et al. Neuromuscular blockers in early acute respiratory distress syndrome. N Engl J Med 2010;363(12):1107-1116.

15. Patki A, Shelgaonkar VC. A comparison of equisedative infusions of propofol and midazolam for conscious sedation during spinal anesthesia: a prospective randomized study. J Anaesthesiol Clin Pharmacol 2011;27(1):47-53.

16. Barr J, Fraser GL, Puntillo K, Ely EW, Gélinas C, Dasta JF, et al. Clinical practice guidelines for the management of pain, agitation, and delirium in adult patients in the intensive care unit: executive summary. Am J Health Syst Pharm 2013;70(1):53-58.

17. Bishop MJ. Hemodynamic and gas exchange effects of pancuronium bromide in sedated patients with respiratory failure. Anesthesiology 1984;60(4):369-371.

18. Coggeshall JW, Marini JJ, Newman JH. Improved oxygenation after muscle relaxation in adult respiratory distress syndrome. Arch Intern Med 1985;145(9):1718-1720.

19. Conti G, Vilardi V, Rocco M, DeBlasi RA, Lappa A, Bufi M, et al. Paralysis has no effect on chest wall and respiratory system mechanics of mechanically ventilated, sedated patients. Intensive Care Med 1995;21(10):808-812.

20. Gainnier M, Roch A, Forel JM, Thirion X, Arnal JM, Donati S, Papazian L. Effect of neuromuscular blocking agents on gas exchange in patients presenting with acute respiratory distress syndrome. Crit Care Med 2004;32(1):113-119.

21. Forel JM, Roch A, Marin V, Michelet P, Demory D, Blache JL, et al. Neuromuscular blocking agents decrease inflammatory response in patients presenting with acute respiratory distress syndrome. Crit Care Med 2006;34(11):2749-2757. 